\title{
Prevalence of Obesity and its Association with Chronic Kidney Disease, Hypertension and Diabetes Mellitus. Isle of Youth Study (ISYS), Cuba
}

\author{
Raúl Herrera Valdés, MD, PhD, DrSc, Miguel Almaguer López, MD, José Chipi Cabrera, MD, Xidix Toirac Cabrera, MD, \\ Orquídea Martínez Soto, MD, Osvaldo Castellanos Rabanal, MD, Jorge Bacallao Gallestey, PhD, Rosa M. Licourt Pérez, MD, \\ Pedro Mulet Pineda, MD, Luisa Diéguez Pérez, MD, Israel Velásquez Batista, MD, María C. Hernández Rivero, MD, Walfrido \\ Caballero Odio, BS, Pedro Urra González, MS, Néstor Rodríguez Triana
}

\begin{abstract}
Introduction Obesity is a social disease constituting a global pandemic. It is present in $90 \%$ of diabetic and $65 \%$ of hypertensive patients. It is associated with cardiometabolic syndrome and with damaging physiopathological mechanisms, particularly for the vascular system and the kidneys. On Cuba's Isle of Youth, a community-based epidemiological study of chronic kidney disease (CKD), hypertension (HTN), diabetes mellitus (DM) and cardio-cerebral vascular disease was carried out in total population, including an examination of common risk factors.
\end{abstract}

Objective Based on the Isle of Youth Study (ISYS) data, determine prevalence of obesity and overweight, and their association with CKD HTN, DM, and shared risk factors for all these conditions in total population of the Isle of Youth, Cuba.

Methods Phase 1: Population diagnosis (November 2004-April 2006): $96.6 \%$ of the Isle of Youth's total population $(80,117)$ was studied, including all ages and both sexes. Information was offered to the public, and written informed consent obtained. Screening was conducted by participant questionnaire including risk factors, physical measurements (weight, height, blood pressure and body mass index), and a single first-morning urine sample to determine the presence of vascular-renal damage markers - proteinuria and hematuria (Combur 10 Test, Roche), and microalbuminuria (Micral Test, Roche). When results were positive, serum creatinine was determined and glomeru- lar filtration rate (GFR) estimated with Modification of Diet in Renal Disease (MDRD) formula for adults and Schwartz formula for children $<15$ years. Data obtained were analyzed to determine association of participants' nutritional status with prevalence of chronic kidney disease, hypertension and diabetes mellitus, as well as a set of common risk factors.

Results Population <20 years: Obesity prevalence $3.2 \%$; positive urine markers in $56.9 \%$ of obese and $8.9 \%$ of non-obese participants; positive albuminuria in $38 \%$ of obese and $3 \%$ of non-obese. Obese participants were found to be hyperfiltrating. DM prevalence was $9.5 \%$ in obese and $1.1 \%$ in non-obese participants. Population $\geq \mathbf{2 0}$ years: Overweight, $31.3 \%$; obese, $13.4 \%$. Positive markers in normal-weight, overweight and obese individuals were $18.3 \%, 21.2 \%$ and $32.7 \%$, respectively; microalbuminuria values increased with weight. Obese individuals were found to be hyperfiltrating. HTN prevalence in normalweight, overweight and obese individuals was $18.3 \%, 31.5 \%$, and $51.0 \%$ respectively; DM rates were $2.8 \%, 5.2 \%$ y $11.3 \%$, respectively.

Conclusion In Cuba, obesity poses significant risk for vascular and renal damage and should be the focus of increased prevention efforts.

Keywords: Vascular diseases, chronic kidney disease, CKD, chronic kidney insufficiency, hypertension, diabetes mellitus, risk factors, obesity, overweight, body mass index, glomerular filtration rate

\section{INTRODUCTION}

Background: After World War II, industrial-scale production was developed to manufacture relatively cheap, easy-to-prepare and highly caloric food products. These became accessible to a share of the global population, among whom obesity has since become a social disease of pandemic proportions.[1]

Global estimates put the number of overweight people at 1.7 billion and obese at 312 million, weight gain directly proportional to the aging of populations. Simultaneously, the new phenomenon of childhood and adolescent obesity already affects 155 million persons worldwide. The largest increase in the obesity pandemic is foreseen in middle-income developing countries.[2-5]

In North America, $49.6 \%$ of Canadians are overweight including $15.7 \%$ obese.[6] Some $66 \%$ of people in the United States are overweight, including 32\% obese.[7] In Mexico, 69\% are overweight, including $30 \%$ obese.[8]
On a social scale: excessive consumption of hypercaloric foods has been associated with genetic predisposition for weight gain, and obese mothers tend to deliver infants of above-average height and weight. The number of overweight and obese children and adolescents is increasing to alarming levels. A family's eating habits can lead to obesity for its members. Among couples with one obese partner, it has been reported that $37 \%$ of spouses follow suit; the same applies to $40 \%$ of twins and $57 \%$ of very close friends.[9]

Obesity often coexists with other risk factors such as smoking and alcohol consumption, and is associated with vascular-damage diseases such as diabetes mellitus (DM), hypertension (HTN) and chronic kidney disease (CKD). Globally, obesity is present in $90 \%$ of type 2 diabetic patients and in $65-75 \%$ of patients with HTN. By 2000, there were 171 million diabetics globally, and their number is expected to reach 366 million by 2030, the largest increase predicted for developing countries. In 2000, 1 billion HTN 
patients were reported, their numbers expected to reach 1.56 billion by 2025.[2]

Diabetes and hypertension are the two main causes of CKD. In the United States, for $72.4 \%$ of patients who started renal replacement therapy in 2003, diabetes or hypertensive vascular disease was the underlying cause of renal failure.[10]

Globally, prevalence of patients in dialysis increases $4-10 \%$ annually, their total number expected to double in this decade.[11] Extrapolating from a study of CKD prevalence carried out in the United States, over 600 million people worldwide may already suffer from some stage of CKD.[12]

A 17-year longitudinal study begun in 1983 of 100,863 subjects aged $\geq 20$ years (Iseki in Okinawa) showed that CKD cumulative incidence increased with body mass index (BMI).[13] Hsu obtained similar results in the United States.[14]

The question then arises: Is obesity just excess fat? Excess fat is only the visible manifestation of obesity, the tip of the iceberg. Inside the body, major metabolic, hormonal, hemodynamic, biochemical, immunological and molecular changes are taking place - the basis for obesity's systemic damage.[15] Thus, obesity is associated with a number of pathological conditions such as:

Cardiometabolic syndrome: Clinical observation has demonstrated frequent association between the anthropometric parameters of obesity (abdominal circumference $\geq 102 \mathrm{~cm}$ in men or $\geq 88$ $\mathrm{cm}$ in women) and metabolic parameters such as lower glucose tolerance $(\geq 110 \mathrm{mg} / \mathrm{dl}$ ) and dyslipidemia (triglycerides $\geq 150 \mathrm{mg} / \mathrm{dl}$, and HDL $<40 \mathrm{mg}$ in men or $<50 \mathrm{mg}$ in women), as well as hemodynamic parameters such as blood pressure $\geq 130 / 80 \mathrm{~mm} \mathrm{Hg}$. Based on this, the US National Cholesterol Education Program has concluded that if three of the above elements are present, a person suffers from cardiometabolic syndrome[16] and thus is at high risk for cardiovascular disease and systemic vascular damage.[17-19] The World Health Organization (WHO) has confirmed this assessment by including albuminuria (a vascular and renal damage marker) as another element to diagnose and describe this syndrome.[20]

Obesity-related glomerulopathy (ORG): In 1974, Weisinger reported an association between nephrotic syndrome and serious obesity.[21] In 1975, Cohen described obesity-related glomerulopathy as characterized by an increase in glomerular volume, slight hypercellularity, variable mesangial enlargement, glomerular basal membrane thickening and, occasionally, segmental and focal sclerosis.[22]

There are two histopathological presentations of ORG: glomerulomegaly and obesity-related focal segmental glomerulosclerosis (O-FSGS). Recent studies indicate (also comparing O-FSGS with primary focal segmental glomerulosclerosis, P-FSGS) that O-FSGS is clinically characterized by moderate proteinuria, little edema, high serum albumin, low cholesterol, lower incidence of nephrotic syndrome and slower progression towards end-stage renal disease (ESRD).[23]

A 15-year study conducted by Kamblan of 6,818 original renal biopsies reported a tenfold increase in the incidence of kidney disease during that period and described the renal histopathology.[24] Optic microscope revealed presence of glomerulomegaly in $100 \%$ of cases; sclerosis was moderate and was not found frequently at the corticomedullary union, as was the case with PFSGS. Moreover, there were perihilar and peripheral segmental lesions, podocytes were hypertrophied, loose and cap-shaped, and pedicels were fused. Particular emphasis was placed on the presence of focal "diabetoid" changes in the form of slight focal mesangial sclerosis and moderate focal thickening of glomerular and tubular basal membranes. Immunofluorescence revealed the presence of IgM and C3 glomerular deposits.

Nephrolithiasis: In a 46-year retrospective study of 4,827 kidney stone patients, Taylor observed that men weighing $>100 \mathrm{~kg}$ had a 1.44 relative nephrolithiasis risk when compared to those weighing $<68 \mathrm{~kg}$. Comparing individuals with a $\geq 30 \mathrm{~kg} / \mathrm{m} 2 \mathrm{BMl}$ to those with a $21-22.9 \mathrm{~kg} / \mathrm{m} 2 \mathrm{BMI}$, he found that the relative risk was 1.33 for men and 1.90 for women.[25] Taylor concluded that hyperinsulinism reduced ammoniogenesis and thus urine $\mathrm{pH}$, and caused hypocitraturia and increased calcium excretion. Moreover, obese individuals also excreted more uric acid and oxalate. The combination of these factors facilitated development of kidney stones.

Objective: Based on ISYS data, the objective of this research was to determine prevalence of obesity and overweight, and their association with chronic kidney disease (CKD), hypertension (HTN), diabetes mellitus (DM), and shared risk factors for these conditions in total population of the Isle of Youth, Cuba.

\section{METHODS}

The first phase of the "Community-Based Epidemiological Study of Chronic Kidney Disease, Cardiovascular Disease, Diabetes Mellitus and Hypertension (ISYS)" was carried out in total population on the Isle of Youth, Cuba, November 2004-April 2006. Phase 1 consisted of active screening for renal-vascular damage markers and associated risk factors for CKD and chronic vascular diseases in total population.

ISYS' general methodology has been published previously.[26] Particularly relevant is the fact that the Isle of Youth's population is composed of a representation of all Cuban provinces, and its age and gender demographics closely resemble those of the rest of the country, except for persons aged $>60$ years, whose percentage on the Isle of Youth is slightly lower.[27] Of the 80,117 persons physically resident in the Isle of Youth, distributed in 21,115 family-household units, $77,423(96.6 \%)$ were screened; their demographics the same as the Isle's total.

CKD was used as a tracer disease in the ISYS study since both renal damage and vascular damage markers can be detected in urine, thus revealing the presence of other chronic vascular diseases.

During Phase 1 of ISYS, public information about the study was provided, and written informed consent obtained from participants. A survey was conducted on family and individual history of vascular disease and risk factors, using the Framingham score.[28] Blood pressure, weight and height were measured. In 
a single first-morning urine sample, vascular and renal damage markers were studied: hematuria and proteinuria (Combur-10 Test, Roche) in total population screened, and microalbuminuria (Micral Test, Roche) in risk groups. Risk groups for vascular-renal damage were defined as individuals with obesity, HTN, DM, a history of CKD or chronic vascular disease, children aged $<5$ years and adults $>60$ years.

A cohort of 14,322 individuals $(18.5 \%)$ was obtained, who tested positive for these markers. Blood samples were taken to determine serum creatinine and glomerular filtration rate (GFR), estimated with MDRD (Modification of Diet in Renal Disease) formula for persons aged $\geq 15$ years and with Schwartz's formula for children aged 2-15 years. CKD stages were then classified for those aged $\geq 2$ years: stage $1, \geq 90$ $\mathrm{ml} / \mathrm{min}$; stage 2, 89-60 $\mathrm{ml} / \mathrm{min}$; stage $3,59-30 \mathrm{ml} / \mathrm{min}$; stage 4, $29-15 \mathrm{ml} / \mathrm{min}$; stage $5,<15 \mathrm{ml} / \mathrm{min}$. Stages were correlated with population demographics, two risk factors (obesity or overweight and age) and other chronic vascular diseases (DM and HTN in population aged $\geq 20$ years and DM in those $<20$ years).

The screened population was divided into age groups, and nutritional status was determined by body mass index (BMI $=\mathrm{kg} /$ $\mathrm{m}^{2}$ ). Population aged $\geq 20$ years were classified as: underweight, $<18.5 \mathrm{~kg} / \mathrm{m}^{2}$; normal weight, $18.5-24.9 \mathrm{~kg} / \mathrm{m}^{2}$; overweight, 25.0 $29.9 \mathrm{~kg} / \mathrm{m}^{2}$; and obese, $\geq 30.0 \mathrm{~kg} / \mathrm{m}^{2}$. For population <20 years, the same BMI formula was used; nutritional status assessment was based on age, sex and percentiles, and persons were classified as obese or non-obese. For this portion of the study, relation between BMI and established risk groups was established for 20,649 children and adolescents aged $<20$ years, and 52,430 adults aged $\geq 20$ years.

All data was introduced into a Microsoft Access database, and a qualitative and quantitative data validation system was employed with minimum and maximum value intervals to minimize error margin.

Frequency distributions of kidney damage markers - proteinuria, proteinuria plus hematuria, microalbuminuria and isolated hematuria - were calculated for cases testing positive within the total population studied. Frequency distributions were constructed to classify renal function, based on GFR estimates for cases aged $\geq 2$ years with positive kidney damage markers whose serum creatinine levels were measured.

Likewise, double-entry tables were created to relate this classification to the following variables for participants aged $\geq 20$ years: sex, age, kidney damage markers, diabetes and hypertension. For participants aged 2-19.9 years, all the above variables were considered except hypertension.

Frequency distributions were calculated for various combinations of four main risk factors: diabetes, hypertension, obesity and overweight. For all combinations, a cross-classification table was also created to reflect status of renal function.

\section{RESULTS}

\section{Population aged $<20$ years}

Obesity prevalence was $3.2 \%$ in this age group. Urine vascularrenal damage markers were positive in $56.9 \%$ of obese and $8.9 \%$ of non-obese individuals. These parameters were similar for all ages within this group. Frequency of each positive marker taken alone was higher in obese than in non-obese individuals.

Positive microalbuminuria within risk groups was $38 \%$ for obese and $3 \%$ for non-obese individuals.

In all ages $<20$ years, obese individuals were hyperfiltrating in comparison to non-obese subjects (Figure 1), an expression of glomerular capillary hypertension, which induces kidney damage.

DM prevalence for this age group was $1.3 \%-9.5 \%$ for obese and $1.1 \%$ for non-obese individuals. This distribution was the same for all ages within this group (Figure 2).

\section{Population aged $\geq 20$ years}

In the adult population, nutritional status analysis revealed $6.0 \%$ underweight, and $44.6 \%$ with $\mathrm{BMI} \geq 25 \mathrm{~kg} / \mathrm{m}^{2} ; 31.3 \%$ were overweight and $13.4 \%$ obese. Overweight and obesity increased with age and risk was higher after 40 years. Percentage of underweight persons increased from age 60 years forward.

Figure 1: Obesity and Glomerular Filtration Rate (GFR) in Population $<20$ Years by Age Group; ISYS, Cuba

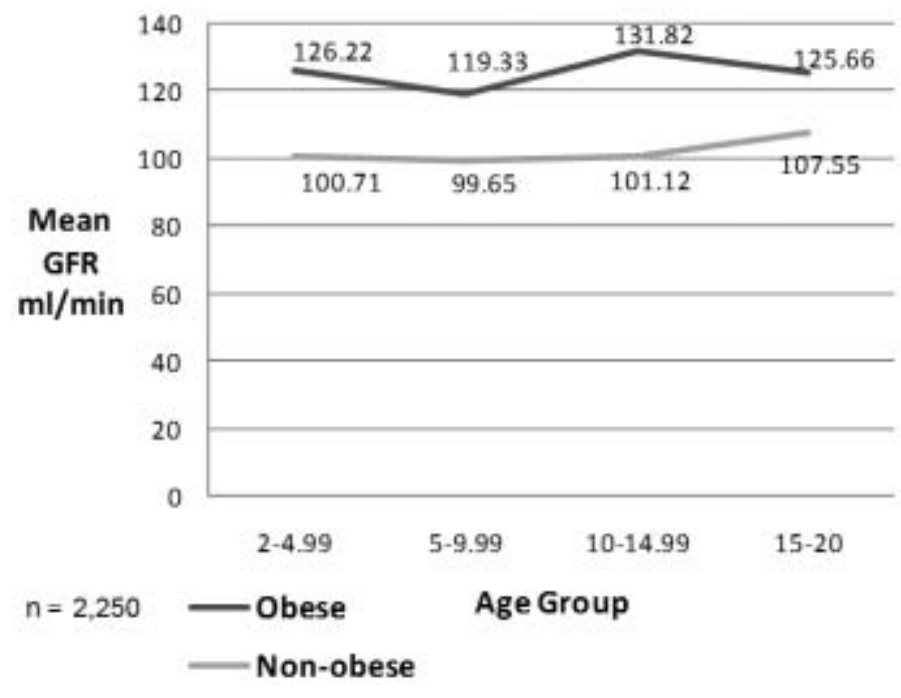

Figure 2: Obesity and Prevalence of Diabetes Mellitus (DM) in Population <20 Years by Age Group; ISYS, Cuba

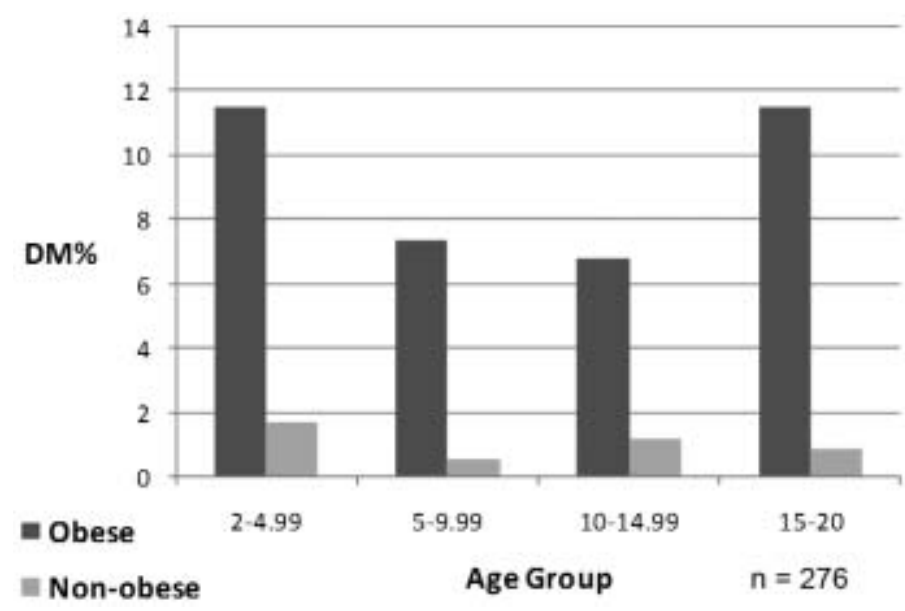


Correlating nutritional status with positive urine markers revealed higher risk among persons underweight $(46.5 \%)$ or obese $(32.7 \%)$ than among persons of normal weight $(18.3 \%)$ or who were overweight $(21.2 \%)$, although the risk was higher in the latter than in those whose weight was normal. Higher risk for individuals at both extremes of nutritional status was present in all age groups, but older age brought added risk of obesity and, after 70, risk distribution took the form of a U-shaped curve (Figure 3).

Figure 3: Nutritional Status and Positive Vascular and Renal Damage Markers in Urine by Age Group; ISYS, Cuba

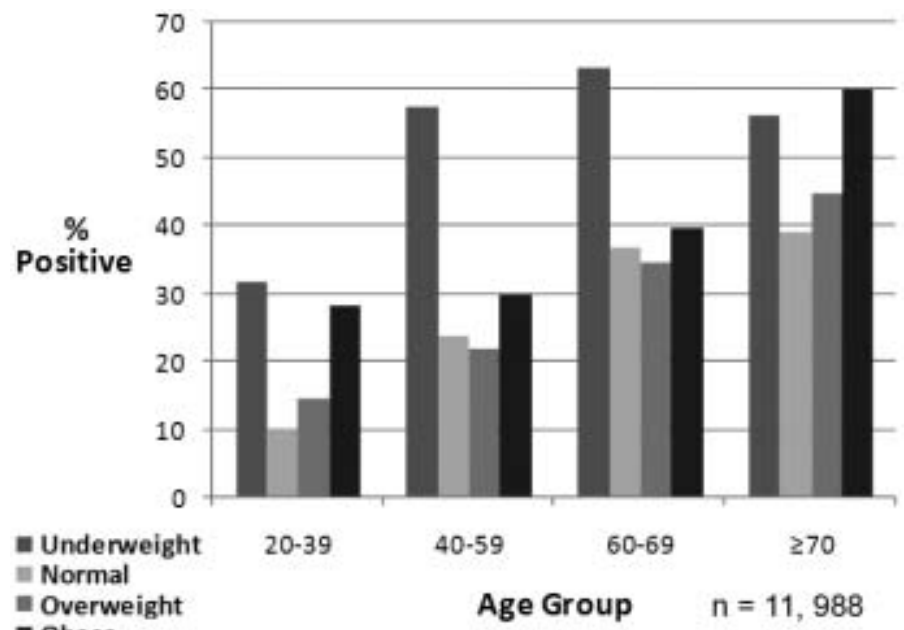

- Obese

Figure 4: Nutritional Status and Microalbuminuria in Risk Population $\geq 20$ Years by Age Group; ISYS, Cuba

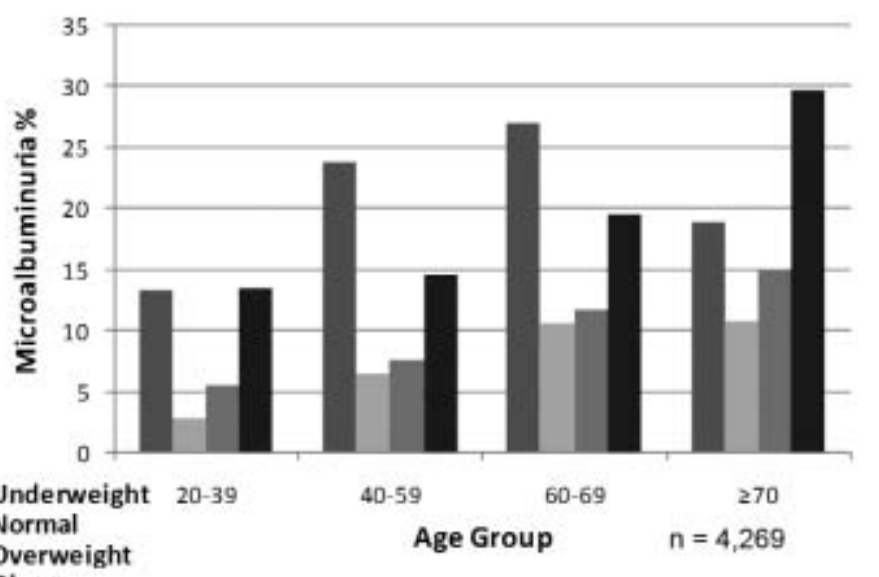

- Overweight

Obese

Among risk groups, positivity for microalbuminuria was high in underweight persons in all age groups; it increased proportionately with weight above normal ranges (overweight, obese) and with age (Figure 4).

In the adult population, underweight, normal-weight, overweight and obese subjects had mean GFR values of $107 \mathrm{ml} / \mathrm{min}, 91 \mathrm{ml} /$ $\min , 101 \mathrm{ml} / \mathrm{min}$ and $127 \mathrm{ml} / \mathrm{min}$, respectively, for a J-shaped curve with the highest point at obesity.

HTN prevalence correlated directly with weight gain, reaching its peak in obese individuals, among whom $51 \%$ were hypertensive, while mean prevalence in adults was $26.5 \%$. HTN prevalence was
$13.3 \%$ in underweight individuals, $18.3 \%$ in normal-weight, and $31.5 \%$ in overweight. Stratifying correlation between hypertension and nutritional status by age group revealed exactly the same tendency, where age was compounded by obesity (Figure 5).

DM also increased with greater weight, and DM prevalence nearly tripled in obese persons $(11.3 \%)$ when compared to DM in the adult population (4.7\%). Prevalence in underweight,

Figure 5: Nutritional Status and Hypertension (HTN) in Population $\geq 20$ Years by Age Group; ISYS, Cuba

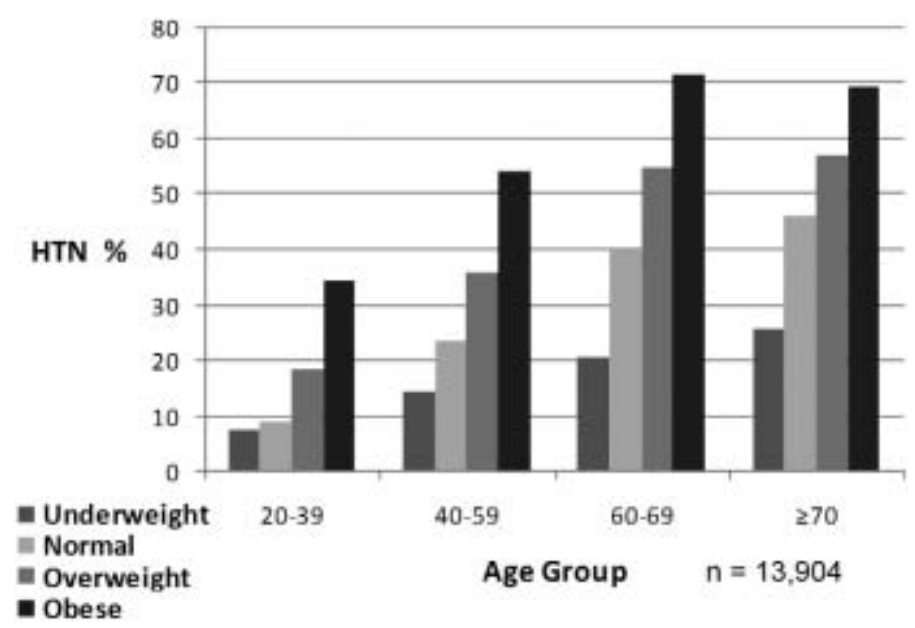

Figure 6: Nutritional Status and Diabetes Mellitus (DM) in Population $\geq 20$ Years by Age Group; ISYS, Cuba

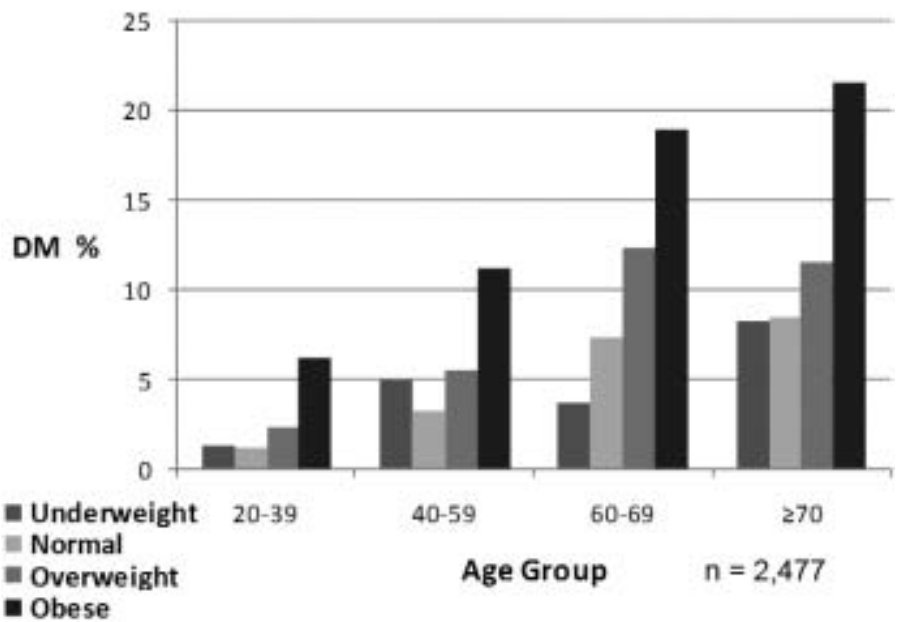

normal-weight and overweight persons was 3.6\%, 2.8\% and $5.2 \%$, respectively. This tendency was observed in all adult age groups, and prevalence increased with age (Figure 6).

Classifying CKD by stages and correlating to nutritional status revealed a higher percentage of persons who were overweight or obese in stages 2 and 3 of renal failure, in contrast with those whose weight was normal or low (Table 1). Age-adjusted risk analysis for adults, calculated without considering HTN and DM, showed a linear gradient of greater risk with increased age.

Risk quantification adjusted for nutritional status, without HTN and DM, clearly revealed the same inverted-J risk distribution ob- 
Table 1: Stage of Chronic Kidney Disease (CKD) and Nutritional Status in Population $\geq 20$ Years (MDRD Formula); ISYS, Cuba

\begin{tabular}{lrrrrr} 
& \multicolumn{5}{c}{ CKD Stage } \\
& $\mathbf{1}$ & $\mathbf{2}$ & $\mathbf{3}$ & $\mathbf{4}$ & $\mathbf{5}$ \\
Underweight & $63.0 \%$ & $30.8 \%$ & $5.0 \%$ & $0.2 \%$ & $1.0 \%$ \\
Normal & $59.0 \%$ & $34.3 \%$ & $5.6 \%$ & $0.6 \%$ & $0.5 \%$ \\
Overweight & $54.3 \%$ & $39.1 \%$ & $6.0 \%$ & $0.2 \%$ & $0.4 \%$ \\
Obese & $52.5 \%$ & $40.6 \%$ & $6.3 \%$ & $0.5 \%$ & $0.2 \%$
\end{tabular}

served earlier. Normal weight was associated with a lower risk, followed by overweight. The increased risk resulting from both underweight and obesity was noted.

\section{DISCUSSION}

In both the young and adult populations, frequency of vascular and renal damage markers in urine as well as HTN and DM prevalence were higher among obese persons, whose renal function was also more deteriorated. Several obesity-inherent physiopathological mechanisms are responsible for the vascular and kidney damage found in these patients (Box).

Observing the last 15 years in Cuba, prevalence of obesity decreased in the mid 1990s and has gradually increased during subsequent years. Several studies bear this out. In Havana's 10 de Octubre municipality, adults were studied between 1988 and1994, obtaining an obesity prevalence of $18.8 \%$ and $6.3 \%$, respectively.[29] Other research has revealed an obesity prevalence in Havana Province of $11.9 \%$ (1982), $5.4 \%(1994)$ and $9.3 \%$ (1998); in Cienfuegos Province, of $14.3 \%$ (1990), $7.2 \%$ (1995) and $12.1 \%$ (2001).[30]

The decline observed in obesity prevalence coincided with reduced food consumption by the Cuban population during the country's severe economic crisis of the 1990s, known as the "Special Period".

The 2nd National Survey on Risk Factors and Chronic Diseases in the Cuban Population[31] carried out in 2000-2001 showed $42.5 \%$ of persons aged $>15$ years with $\mathrm{BMl}>24.9$ $\mathrm{kg} / \mathrm{m}^{2}$, of whom $11.8 \%$ were obese (BMI>30). ISYS data obtained among adults coincide with these earlier results, and constitute a call for prevention of continued increase in obesity prevalence.
ISYS results show that risk of vascular-renal damage is as great for underweight as for obese persons. One hypothesis to explain this finding is that among the underweight cohort are the most elderly people, who may have been nutritionally compromised due to kidney damage, as well as those who suffer from type 1 diabetes from an early age. This group should be studied separately and more thoroughly.

ISYS results corroborate that obesity in Cuba is a risk factor for atherosclerosis-linked chronic vascular disease, a risk that increases with age. These vascular diseases clinically manifest in different forms depending on the main organ affected, usually presenting co-morbidity in which each condition enhances the damage of the other, constituting a systemic multiplier of damage. As shown in previous studies, overweight and obesity in Cuba is gradually increasing, a situation that merits particular and comprehensive attention by all sectors that influence the population's health

\section{Physiopathological Mechanisms of Obesity Responsible for Vascular and Renal Damage}

Adipose tissue is an active endocrine organ that secretes several adipokines with auto-, para-, and endocrine effects that have inflammatory, mitogenic, hemodynamic and other functions. Adipokines include: leptin, adiponectin, resistin, angiotensin II (AgII), TNF- $\alpha$, PAl-1, interleukin (IL)-1-6-8-10, prostaglandins, HGF, VEGF, IGF-1, estrogens, and others. Visceral adipose tissue has more endocrine activity and increases structurally and functionally with obesity; thus the importance of abdominal obesity.[32,33]

An excess of adipokines reduces the amount of glucose-transporting intracellular proteins (Glut 1-Glut 4). Concurrently, obesity increases cell endoplasmic reticulum stress. The combination of these two factors causes an increase in tissue resistance to insulin, which results in hyperinsulinism. $[20,34,35]$ Hyperinsulinism acts on various biomolecules and their receptors causing:

- Increased sympathetic activity, salt sensitivity and Agll and ET levels and decreased nitric oxide and natriuresis, leading to systemic hemodynamic changes, hypertension and systemic vascular damage;

- Increased glomerular capillary pressure, hyperfiltration, podocyte damage and albuminuria; and

- Release of mitogenic factors (IGF-1, TGF- $\beta$, PAI-1) that induce mesangial cell proliferation and greater glomerular matrix deposition.

HTN and efferent arteriole vasoconstriction generated by adipokines and hyperinsulinism increase glomerular capillary pressure. At the same time, the metabolic demand resulting from increased body fat increases cardiac output and renal plas- ma flow, resulting in greater glomerular capillary hypertension, hyperfiltration and albuminuria, leading to tubulointerstitial damage.[36]

Mononuclear cells in the adipose tissue matrix produce oxidizing radicals, with well-known deleterious systemic effects which, added to those caused by Agll and TGF- $\beta$ induction, causes an increased glomerular matrix deposition.[37] Obesity increases the reactivity of medullary baroreceptors, thus increasing the adrenosympathetic activity-another mechanism that contributes to HTN.[15]

Seventy-five percent of people with sleep apnea are obese. Apnea causes hypoxia, which releases so-called "hypoxia-induced factors (HIF)"; these allow cells to adapt to low oxygen levels. The persistence and intensity of this physiological mechanism causes inflammatory cell infiltration and higher levels of TGF- $\beta$, CTGF, metalloproteinase inhibitors and PAl-1, which cause inflammation, apoptosis, podocyte damage, and renal fibrosis.[38]

Physiopathological changes prompted by obesity include: increased production of adipokines, hyperinsulinism, dyslipidemia, glomerular capillary hypertension, oxidative stress, stimulation of the renin-angiotensin-aldosterone system, hypoxia, inflammation and others. These integrate agonistically into a perpetual system of kidney cell damage. Kidney cells do not remain a passive target: not only are they damaged but they also react and change phenotypically. They are transformed into immunocompetent cells which become hypertrophied, proliferate, present antigens, and liberate vasoactive factors, inflammatory cytokines, growth factors, matrix proteins, etc. This results in a reverberating damage-producing system leading to glomerulosclerosis and accelerating progression of any underlying renal disease, also causing primary kidney disease.[39-42] 
At the same time, ISYS provides further evidence that obesity should be understood as a chronic disease that is genetically based, social in origin, and pandemic in behavior. It is expressed externally by excess fatty accumulation and internally by profound metabolic disturbances, and poses increased risk for development of chronic vascular conditions. - s

\section{REFERENCES}

1. Eknoyan G. A history of obesity, or how what was good became ugly and then bad. Adv Chron Kidney Dis. 2006; 13(4):421-27.

2. Hossain P, Kawar B, Nahas ME. Obesity and diabetes in the developing world - A growing challenge. N Engl J Med. 2007; 356(9):973-77.

3. Doyle M, Siegel R, Supe K. Stages of change and transitioning for adolescent patients with obesity and hypertension. Adv Chron Kidney Dis. 2006; 13(4):386-93.

4. Wang Y, Chen X, Klag MJ, Caballero B. Epidemic of childhood obesity: Implications for kidney disease. Adv Chron Kidney Dis. 2006; 13(4):33651.

5. Douglas Williams J, Tremblay MS, Katzmarzyk PT. Geographic and demographic variation in the prevalence of overweight Canadian children. Obes Res. 2003; 11:668-73.

6. Katzmarzyk PT, Mason C. Prevalence of class I, II and III obesity in Canada. CMAJ. 2006; 174(2):156-7. Online table (www.cmaj.ca/cgi/ content/full/174/2/156/DC1) consulted Jan 8, 2008.

7. Oqden $\mathrm{CL}$, Carroll MD, Curtin LR, McDowell MA et al. Prevalence of overweight and obesity in the United States, 1999-2004. JAMA. 2006; 295:1549-55.

8. Encuesta Nacional de Salud y Nutrición. Informe de Salud México, 2001-2005. México, D.F. (MX): Secretaría de Salud; 2005.

9. Christakis NA, Fowler JH. The spread of obesity in a large social network over 32 years. $\mathrm{N}$ Engl J Med. 2007; 357(4):370-79.

10. United States Renal Data System 2005 Annual Data Report. Am J Kidney Dis. 2006; 47(1 suppl1):10

11. Xue JL, Ma JZ, Louis TA, Collins AJ. Forecast of the number of patients with end-stage renal disease in the United States to the year 2010. J Am Soc Nephrol. 2001; 12:2753-58.

12. Centers for Disease Control and Prevention. Prevalence of chronic kidney disease and associated risk factors - United States, 1999-2004. MMWR Morb Mortal Wkly Rep. 2007; 56(8):161-65.

13. Iseki K, Ikemiya Y, Kinjo K, Inoue T, Iseki Ch, Takishita S. Body mass index and the risk of development of end-stage renal disease in a screened cohort. Kidney Int. 2004; 65:1870-76.

14. Hsu C, McCulloch CE, Iribarren C, Darbinian J, Go AS. Body mass index and risk for end-stage renal disease. Ann Intern Med. 2006; 144:21-28.

15. Chalmers L, Kaskel FJ, Bamgbola O. The role of obesity and its bioclinical correlates in the progression of chronic kidney disease. Adv Chron Kidney Dis. 2006;13(4):352-64.

16. National Cholesterol Education Program (NCEP). Expert panel on detection, evaluation, and treatment of high blood cholesterol in adults (adult treatment panel III). Third report of the National Cholesterol Education Program expert panel on detection, evaluation, and treatment of high blood cholesterol in adults (Adult Treatment Panel III) final report. Circulation. 2002; 106:3143-3421.

17. Chertow GM, Hsu Chy, Johansen KL. The enlarging body of evidence: obesity and chronic kidney disease. J Am Soc Nephrol. 2006; 17:1695-02.

18. Bagby SP. Obesity-initiated metabolic syndrome and the kidney: A recipe for chronic kidney disease? J Am Soc Nephrol. 2004; 15:2775-91.
19. Tanaka H, Shiohira Y, Uezu Y, Higa A, Iseki K. Metabolic syndrome and chronic kidney disease in Okinawa, Japan. Kidney Int. 2006; 69:369374.

20. Lastra G, Manrique C, Sowers JR. Obesity, cardiometabolic syndrome, and chronic kidney disease: the weight of the evidence. Adv Chron Kidney Dis. 2006;13(4):365-73.

21. Weisinger JR, Kempson RL, Eldridge L, Swenson RS. The nephritic syndrome. A complication of massive obesity. Ann Int Med. 1974; 81:44047.

22. Cohen $\mathrm{AH}$. Massive obesity and the kidney. A morphologic and statistical study. Am J Pathol. 1975; 81:117-30.

23. Charles J, Charles L, Grubb W. Glomerulomegaly and focal segmental glomerulosclerosis associated with obesity and sleep-apnea syndrome. Am J Kidney Dis. 1987;10(6):470-72.

24. Kamblam N, Markowitz GS, Valeri AM, Lin J, D'Ágati VD. Obesity-related glomerulopathy: An emerging epidemic. Kidney Int. 2001; 59:149809.

25. Taylor EN, Stampfer MJ, Curhan GC. Obesity, weight gain, and the risk of kidney stones. JAMA. 2005; 293: 455-62.

26. Almaguer López $\mathrm{M}$, Herrera Valdés R, Chipi Cabrera J, et al. Design and methodology of the Isle of Youth community-based epidemiological study of CKD, cardio-cerebral vascular disease, hypertension, and diabetes mellitus (ISYS). MEDICC Review. 2007; 9(1):23-30.

27. Ministerio de Salud Pública, Dirección Nacional de Registros Médicos y Estadísticas de Salud. Anuario Estadístico de Salud 2006. Havana: Ministerio de Salud Pública; 2007.

28. Kannel WB, Feinleib M, McNamara PN, Garrison RJ, Castelli WP. An investigation of coronary heart disease in families. The Framingham offspring study. Am J Epidem. 1979; 110(3):281-90.

29. Debs Pérez G, de la Noval García R, Dueñas Herrera A, et al. Prevalencia de factores de riesgo coronario en 10 de Octubre. Su evolución a los 5 años. Rev Cub Card Cir Card. 2001;15:1420.

30. Franco $M$, Ordúñez $P$, Caballero $B$, et al. Impact of energy intake, physical activity, and population wide weight-loss on cardiovascular disease and diabetes mortality in Cuba, 1980- 2005. Am J Epid. 2007;19:1-7.

31. Jiménez-Acosta S, Díaz-Sánchez ME, Barroso I, et al. Estado nutricional de la población cubana adulta. Rev Españ Nutr Comunit. 2005; 11:1826.

32. Fawcett DW. Tejido adiposo. In:Tratado de histología. Ed. Interamericana, Madrid: McGrawHill; 1995.

33. Chudek J, Adamczak M, Nieszporek T, Wiecek A. The adipose tissue as a source of vasoactive hormones and cytokines with a potential role in the pathogenesis of cardiovascular and renal diseases. Rev Port Nefrol Hipert. 2006; 20(2):8191.

34. Hanley A, Wagenknecht L, D'Agostino RJ, Zinman $B$, Haffner S. Identificación de individuos con resistencia insulínica y disfunción de la célula beta utilizando definiciones alternativas del síndrome metabólico. Diabetes. 2003; 52:2740-47.

35. Chen J, Muntner P, Hamm LL, Fonseca V, Batuman $\mathrm{V}$, et al. Insulin resistance and risk of chronic kidney disease in nondiabetic US adults. J Am Soc Nephrol. 2003; 14:469-77.

36. Srivastava T. Nondiabetic consequences of obesity on kidney. Pediatr Nephrol. 2006; 21:46370.

37. Dandona P, Mohanty P, Ghanim H, et al. The suppressive effect of dietary restriction and weight loss in the obese on the generation of reactive oxygen species by leucocytes lipid peroxidation, and protein carbonylation. J Clin Endocrinol Metab. 2001; 86:355-362.

38. Eckardt $\mathrm{K}-\mathrm{U}$, Bernbardt W, William C, Wiesener M. Hypoxia-inducible transcription factors and their role in renal disease. Sem Nephrol. 2007; 27(3):363-72.

39. Praga M, Morales E. Obesity, proteinuria and progression of renal failure. Cur Opin Nephrol Hypert. 2006; 15(5):481-86.

40. Kaysen GA. Role of inflammation and its treatment in ESRD patients. Blood Purif. 2002; 20:7080.

41. Johnstone DB, Holzman LB. Clinical impact of research on the podocyte slit diaphragm. Nat Clin Pract Nephrol. 2006; 2(5):271-82.

42. Herrera Valdés R. Mecanismos de daño en la enfermedad glomerular y la repercusión túbulointersticial. In: Treviño Becerra A, editor. Tratado de Nefrología. Mexico City: Editorial Prado; 2003.

\section{THE AUTHORS}

Raúl Herrera Valdés (Corresponding Author: raul.herrera@infomed.sld.cu) specialist in nephrology, full professor, Higher Institute of Medical Sciences of Havana, senior researcher and academician, Institute of Nephrology, Havana, Cuba.

Miguel Almaguer López, specialist in nephrology, associate professor, Higher Institute of Medical Sciences of Havana, senior researcher, Chief of Preventive Nephrology Services, Institute of Nephrology, Havana, Cuba.

José Chipi Cabrera, specialist in nephrology, instructor, Isle of Youth Faculty of Medicine, Head of Nephrology Service, Héroes de Baire Hospital, Isle of Youth, Cuba.

Xidix Toirac Cabrera, specialist in rheumatology, Héroes de Baire Hospital, Isle of Youth, Cuba.

Orquídea Martínez Soto, specialist in nephrology, Héroes de Baire Hospital, Isle of Youth, Cuba.

Osvaldo Castellanos Rabanal, specialist in epidemiology, Municipal Health Director, Isle of Youth, Cuba. 


\section{Original Scientific Articles}

Jorge Bacallao Gallestey, professor, Higher Institute of Medical Sciences of Havana, Atherosclerosis Research and Reference Center, Havana, Cuba.

Rosa M. Licourt Pérez, specialist in family medicine, Dr. Juan M. Páez Incháustegui Teaching Polyclinic, Isle of Youth, Cuba.

Pedro Mulet Pineda, specialist in family medicine, Dr. Juan M. Páez Incháustegui Teaching Polyclinic, Isle of Youth, Cuba.

Luisa Diéguez Pérez, specialist in family medicine, Leonilda Tamayo Matos Teaching Polyclinic, Isle of Youth, Cuba.
Israel Velásquez Batista, specialist in family medicine, Dr. Juan M. Páez Incháustegu Teaching Polyclinic, Isle of Youth, Cuba.

María C. Hernández Rivero, specialist in family medicine, Orestes Falls Oñate Teaching Polyclinic, Isle of Youth, Cuba.

Walfrido Caballero Odio, nurse, Orestes Falls Oñate Teaching Polyclinic, Isle of Youth, Cuba.

Pedro Urra González, Director, National Medical Sciences Information Center and founder and Director of INFOMED, Havana, Cuba.

Néstor Rodríguez Triana, Informatics Department, Héroes del Baire Hospital, Isle of Youth, Cuba.

\section{ACKNOWLEDGMENTS}

We wish to thank the over 350 family physicians and nurses and other health professionals and ICT (Information and Communication Technologies) experts and specialists from the Isle of Youth Health Department, INFOMED, the University of Computer Sciences, the Institute of Nephrology and the Ministry of Public Health (MINSAP), for their participation in Phase 1 of the Isle of Youth Study (ISYS).

Submitted: October 1, 2007

Approved for publication: February 12, 2008 